\title{
PENGALAMAN PASANGAN HIDUP DALAM MENDAMPINGI PENGOBATAN PASIEN MULTIDRUG RESISTANT TUBERCULOSIS (MDR TB) LIFE PARTNER'S EXPERIENCE IN ASSISTING TREATMENT OF MDR TB
PATIENT
}

\author{
Sakti Vivendi Rosa Widyastuti ${ }^{1}$, Meira Erawati ${ }^{2}$, Reni Sulung Utami ${ }^{3}$, Nur Setiawati Dewi ${ }^{4}$ \\ ${ }^{1}$ Mahasiswa Magister Keperawatan, Fakultas Kedokteran, Universitas Diponegoro \\ ${ }^{2,3,4}$ Dosen Magister Keperawatan, Fakultas Kedokteran, Universitas Diponegoro \\ email : sakti.vivendirosawidyastuti@gmail.com
}

\begin{abstract}
ABSTRAK
Latar belakang: pasien Multidrug Resistant Tuberculosis (MDR TB) merupakan orang yang resisten terhadap obat isoniazid dan rifampisin. Dukungan keluarga terutama pasangan hidup diperlukan ketika pasien MDR TB menjalani pengobatan. Pasangan hidup mempunyai peran penting dalam keberhasilan pengobatan. Tujuan: mengeksplorasi pengalaman pasangan hidup dalam mendampingi pasien yang menjalani pengobatan MDR TB. Metode: penelitian ini merupakan penelitian kualitatif dengan menggunakan pendekatan studi kasus untuk mengeksplorasi bagaimana pengalaman pasangan hidup pasien MDR TB dalam mendampingi dan mendukung pasien yang menjalani pengobatan MDR TB. Partisipan: pemilihan partisipan menggunakan purposive sampling yaitu pasangan hidup yang aktif mendampingi pasien MDR TB dalam menjalani pengobatan. Jumlah partisipan pada penelitian ini adalah tiga orang. Hasil: penelitian ini dapat dikategorikan menjadi dua tema yaitu tantangan dalam merawat pasangan yang menderita MDR TB dan pasrah dalam menjalani hidup. Kesimpulan: pasangan hidup pasien MDR TB memiliki sikap dan perasaan khawatir terhadap kepatuhan pengobatan pasangan, kecemasan jika pengobatan MDR TB tidak berhasil dan terjadi kekambuhan pada pasangan.
\end{abstract}

Kata Kunci:Tuberkulosis resisten obat, Pasangan Hidup, Pendampingan, Pengobatan

\begin{abstract}
Background: Multidrug-Resistant Tuberculosis (MDR TB) patients are resistant to isoniazid and rifampin drugs. Family support, especially life partners, is needed when MDR TB patients undergo treatment. Life partner has an essential role in the success of treatment. Purpose: to explore experiences of life partners in assisting patients undergoing MDR TB treatment. Methods: This study is a qualitative study using a case study approach to explore how the experiences of life partners of MDR TB patients accompany and support patients undergoing MDR TB treatment. Participants: Participants' selection using purposive sampling, namely partners who actively accompany MDR TB patients in undergoing treatment. The number of participants in this study was three people. Results: We categorized the results into two themes: the challenges in caring for a partner suffering from MDR TB and resigning themselves to life. Conclusion: the spouse of MDR TB patients has an attitude and feelings of worry about partner treatment adherence, anxiety if MDR TB treatment is not successful, and a recurrence occurs in the partner.
\end{abstract}

Keywords: drug-resistant tuberculosis, partner, mentoring, medication 


\section{LATAR BELAKANG}

Multidrug Resistant Tuberculosis (MDR TB) merupakan penyakit infeksi menular yang mematikan nomor satu di Indonesia (Manari et al., 2011). World Health Organization (WHO) menyebutkan capaian angka keberhasilan pengobatan MDR TB di benua Asia pada tahun 2016 hanya mencapai 52\% (WHO, 2019). WHO mencatat di negara Indonesia pada tahun 2016 capaian angka keberhasilan pengobatan MDR TB hanya mencapai $48 \%$ atau 37\% lebih rendah dari target yang ditentukan (Safri, Sukartini, \& Ulfiana, 2019). Keberhasilan pengobatan MDR TB yang rendah menyebabkan penyakit MDR TB bisa kambuh dan berkembang menjadi extensive drugs tuberculosis (Fonner \& Drph, 2013; Manari et al., 2011).

Pasien MDR TB pernah mendapatkan terapi obat anti tuberkulosis sebelumnya dan menjadi resisten terhadap obat jenis isoniazid dan rifampicin karena beberapa faktor (Manari et al., 2011). Kementerian Kesehatan Indonesia melakukan penelitian tentang faktor penyebab timbulnya MDR TB disebabkan tiga hal yaitu faktor dari petugas kesehatan, program pengendalian tuberkulosis dan pasien. Faktor pasien yaitu pasien tidak mentaati anjuran dari petugas kesehatan, pasien tidak teratur menelan obat anti tuberkulosis, pasien memutuskan pengobatan secara sepihak sebelum waktu yang telah disepakati, dukungan keluarga terhadap pengobatan dan gangguan penyerapan obat anti tuberculosis (Kementerian Kesehatan RI, 2018). Data Riset Kesehatan Dasar (Riskesdas) pada tahun 2018 menyebutkan bahwa faktor yang menyebabkan pasien MDR TB yaitu tidak rutin minum obat yaitu sering lupa minum obat, obat tidak tersedia, tidak tahan efek samping obat, masa pengobatan terasa lama, tidak mampu membeli obat, tidak rutin berobat, kurangnya dukungan keluarga untuk mengawasi minum obat dan merasa sudah sembuh (Kementerian Kesehatan RI, 2018).

Dukungan keluarga dalam pengobatan MDR TB terbukti mampu meningkatkan keberhasilan pengobatan MDR TB. Sebaliknya dukungan keluarga yang buruk terhadap pengobatan MDR TB bisa mengurangi motivasi untuk menjalani pengobatan MDR TB. Dukungan keluarga mempengaruhi perilaku pasien dalam menjalani pengobatan (Fonner \& Drph, 2013).

Faktor yang mempengaruhi keberhasilan pengobatan yaitu dukungan keluarga dekat terutama pasangan hidup. Pasangan hidup mempunyai peran penting dalam kepatuhan pengobatan karena adanya kedekatan batin antara suami istri. Pasangan hidup merupakan orang yang selalu setia mendampingi pasien MDR TB selama sakit dan menjalani pengobatan (Aslamiyati et al., 2019).

Pasien MDR TB yang telah mempunyai pasangan hidup juga rentan mengalami persepsi yang buruk terhadap pasangan karena menganggap pasangan rentan tertular penyakit MDR TB. Dukungan dari pasangan dibutuhkan ketika persepsi buruk muncul pada pasien MDR TB (Dewi, Prabamurti, \& Indraswari, 2019). Persepsi baik dapat mempengaruhi pasien melakukan pencegahan penyakit dalam menjalani pengobatan MDR TB. Pasien MDR TB mendapatkan manfaat dari pengobatan dengan harapan sembuh. Harapan sembuh dari pasien MDR TB terutama dipengaruhi oleh dukungan dari pasangan hidup pasien (Nurhayati, Kurniawan, \& Mardiah, 2015).

Persepsi yang baik dari pasien dan pasangan hidup diharapkan mampu meningkatkan kedisiplinan pasien dalam pengobatan tuberkulosis (Manari et al., 2011). Persepsi dan dukungan dari pasangan hidup pada pasien MDR TB masih belum maksimal untuk mendukung pasien menjalani pengobatan MDR TB sehingga perlu dilakukan penelitian lebih lanjut tentang pengalaman pasangan hidup dalam mendampingi pasien menjalani pengobatan MDR TB (Safri et al., 2019). 
Rumusan masalah penelitian ini yaitu bagaimana pengalaman pendamping hidup pasien MDR TB selama mendampingi pengobatan? Tujuan penelitian ini untuk mengetahui dan mengeksplorasi pengalaman dari pasangan hidup pasien MDR TB selama menjalani pengobatan.

\section{METODE}

\section{Desain dan sampel penelitian}

Penelitian ini merupakan penelitian kualitatif dengan menggunakan pendekatan studi kasus. Partisipan dalam penelitian ini yaitu pasangan hidup dari pasien MDR TB yang berjumlah tiga orang. Kriteria inklusi penelitian ini yaitu pasangan hidup dari pasien MDR TB yang sudah menjalani pengobatan minimal satu bulan, bisa berbahasa Indonesia, pasangan hidup mendampingi pasien MDR TB selama kontrol atau berobat ke fasilitas kesehatan. Kriteria eksklusi penelitian ini yaitu pasangan hidup tidak tinggal satu rumah dengan pasien MDR TB dan pasangan hidup tidak menderita penyakit MDR TB.

\section{Pengumpulan data}

Teknik pemilihan partisipan yang digunakan adalah purposive sampling. Partisipan dipilih sesuai dengan kriteria inklusi. Penelitian dilakukan pada bulan Mei tahun 2020. Peneliti melakukan wawancara kepada tiga pasangan hidup pasien MDR TB yang berdomisili di kota Semarang. Peneliti membuat kesepakatan waktu dan tempat dengan partisipan sebelum melakukan wawancara. Wawancara dilakukan dengan metode wawancara mendalam sekitar 10 sampai dengan 20 menit selama tiga kali wawancara pada setiap partisipan. Pada pertemuan pertama, peneliti melakukan wawancara mendalam terkait dengan pengetahuan tentang penyakit, penyebab sakit, lama sakit dan pengobatan penyakit pasangan hidup partisipan. Pada pertemuan kedua, peneliti melakukan wawancara mendalam tentang perasaan partisipan selama mendampingi pasangan hidup menjalani pengobatan. Pada pertemuan ketiga, peneliti melakukan wawancara mendalam tentang harapan dan keinginan partisipan terhadap pengobatan.

\section{Instrumen penelitian}

Peneliti menggunakan pedoman wawancara semi terstruktur, lembar observasi dan alat perekam saat melakukan pengumpulan data. Pedoman wawancara meliputi pertanyaan terkait pengetahuan partisipan tentang penyakit MDR TB, pengalaman partisipan menjadi pasangan dari pasien MDR TB dan harapan terhadap pasangan tentang pengobatan MDR TB.

\section{Analisis data}

Dalam penelitian ini, dilakukan triangulasi data dengan melakukan wawancara kepada partisipan dengan berbagai latar belakang pendidikan dan riwayat pengobatan pasien MDR TB yaitu riwayat pernah mengalami drop out pengobatan, riwayat pengobatan pertama kali dan riwayat pengobatan karena kekambuhan. Peneliti membuat pedoman wawancara berdasarkan literatur yang relevan dan berkonsultasi dengan ahli. Hasil wawancara dilakukan transkrip verbatim dan dianalisis dengan menggunakan analisis konten. Peneliti melakukan analisis data dengan cara mengelompokkan konten kalimat pendukung pada wawancara dari sub kategori, kategori, sub tema dan tema. Kemudian peneliti melakukan analisis dan pembahasan dari hasil tema yang sudah terbentuk. 


\section{Etika penelitian}

Sebelum wawancara, peneliti memberikan informasi kepada partisipan tentang tujuan, manfaat, proses penelitian yang dilakukan. Partisipan yang bersedia mengikuti penelitian menandatangani lembar persetujuan penelitian. Penelitian ini telah dinyatakan layak etik oleh Komisi Etik Penelitian Kesehatan RSUP Dr. Kariadi Semarang dengan sertifikat Ethical Clearance Nomor 461/EC/KEPK-RSDK/2020.

\section{HASIL DAN PEMBAHASAN}

HASIL

Sampel dalam penelitian ini berjumlah tiga partisipan dengan komposisi partisipan dua orang perempuan dan satu orang laki - laki. Pendidikan partisipan adalah dua lulusan SMA dan satu lulusan sarjana. Karakteristik partisipan secara detail dapat dilihat di Tabel 1.

Tabel 1 Distribusi Frekuensi Karakteristik Partisipan

\begin{tabular}{lll}
\hline Karakteristik & Jumlah & Presentase $(\%)$ \\
\hline Jenis Kelamin & & \\
\hline Laki - laki & 1 & 33,33 \\
Perempuan & 2 & 66,67 \\
\hline Usia & & \\
\hline $25-30$ & 1 & 33,33 \\
$30-35$ & 1 & 33,33 \\
$35-40$ & 1 & 33,33 \\
\hline Pendidikan & & \\
\hline SMA/sederajat & 2 & 66,67 \\
Sarjana & 1 & 33,33 \\
\hline Lama pasangan sakit MDR TB & & \\
\hline Kurang dari 5 tahun & 1 & 33,33 \\
Lebih dari 5 tahun & 2 & 66,67 \\
\hline
\end{tabular}

Dari hasil penelitian didapatkan dua tema yaitu tantangan dalam merawat pasangan yang menderita MDR TB dan pasrah dalam menjalani hidup.

\section{Tema 1: Tantangan dalam merawat pasangan yang menderita MDR TB}

Tantangan dalam merawat pasangan di kategorikan terkait dari perubahan fisik pasangan partisipan. Pasangan partisipan mulai terjadi perubahan fisik karena penyakitnya seperti sering mengalami batuk, badan terasa dingin, kadang sering berkeringat.

"Suami saya pernah sakit batuk, dahak berwarna merah dan berkeringat dingin pada malam hari."(P3)

"Istri saya sudah sakit paru hampir 3 tahun.”(P2)

Pasangan partisipan yang mengalami batuk dan tidak paham karena minum obat dikarenakan sulit menelan dan susah makan.

"Istri saya batuk selama satu bulan."(P2)

"Obat suami saya berukuran besar sehingga suami saya mengalami kesulitan menelan.”(P3) 
Tema ini dikategorikan dari ungkapan partisipan terkait kekhawatiran pasangan hidup pada kesembuhan pasien, kesedihan terkait kondisi pasangan hidup, aktivitas baru pasangan hidup, respon pasangan hidup, kecemasan pasangan hidup tentang penyakit pasien, kekhawatiran terkait respon efek samping pengobatan pasien dan usaha pasangan hidup.

"Saya merasa sedih, kenapa tidak saya saja yang sakit. Kenapa harus istri saya. Kalau saya bisa menggantikan istri saya sakit, saya juga ikhlas.”(P2)

"Saya menyadari disuntik tiap hari membuat bosan dan efek samping obat yang besar."(P3)

Pertama kali di diagnosa menderita MDR TB, partisipan mengungkapkan beberapa keluhan yang dialami oleh pasangannya seperti adanya batuk dahak bewarna merah dan keluar keringat dingin saat malam hari.

"Kalau malam sering mengalami keringat tetapi badan merasa dingin dan mengalami batuk merah seperti darah.”(P3)

"Satu bulan batuknya parah tidak berhenti."(P2)

Setelah didiagnosa menderita MDR TB, partisipan mengeluhkan adanya perubahan fisik, emosi dan sosial dari pasangan mereka. Partisipan menyatakan bahwa pasangan mereka sering mengeluhkan badan meriang, sulit makan, mual, muntah dan kelelahan. Kelelahan pasangan mereka dikarenakan adanya rasa bosan dalam menjalani pengobatan MDR TB, dimana pasangan mereka harus rutin minum obat MDR TB dan kontrol ke pelayanan kesehatan.

"Dia merasa sudah lelah dengan kondisi seperti ini tetapi kalau tidak obati akan semakin parah.”(P2)

"Efek samping obat setelah disuntik menjadi badan meriang, mual dan muntah, badan menjadi tidak enak."(P3)

Perubahan emosional juga partisipan ungkapkan terkait pasangan mereka. Seorang partisipan mengungkapkan meningkatnya perasaan sensitif pada pasangan mereka. Secara sosial, tantangan yang dihadapi oleh partisipan adalah perasaan malu menderita TB yang menyebabkan pasangan mereka membatasi pertemuan dengan orang lain. Selain itu, partisipan menggambarkan perubahan perilaku dalam kehidupan rumah tangga mereka. Seorang partisipan mengeluhkan jarangnya aktivitas seksual yang dijalani setelah pasangan mereka menderita penyakit MDR TB.

"Tetangga saya tahu kalau istri saya terkena sakit paru. Sejak sakit istri saya tidak pernah keluar rumah. Dia malu dengan tetangga."(P2)

"Kita di rumah juga dikucilin sama tetangga."(P3)

"Dia merasa malu ketika berkumpul sama dengan orang. Apalagi sekarang musim corona, yang harus memakai masker seperti bapak."(P1)

Upaya yang dilakukan oleh partisipan dalam memberikan perawatan yang optimal pada pasangannya melalui pemberian motivasi, semangat dalam menjalani pengobatan, mendampingi saat berobat ke pelayanan kesehatan dan menasihati terkait kepatuhan berobat dan minum obat. Partisipan juga mulai memisahkan peralatan makan dan minum pasangan dengan anggota keluarga yang lain.

"Saya sebagai istri selalu memberi semangat buat bapak supaya bisa sehat lagi."(P3)

Selain itu, partisipan juga selalu memotivasi diri mereka sendiri untuk bersemangat mendampingi suami menjalani pengobatan, menjauhkan rasa bosan dan rasa capek dalam merawat pasangannya, harus bersikap disiplin kepada pasangan mereka terkait pengobatan yang dijalani dan partisipan juga selalu berdoa kepada Tuhan agar pasangan mereka diberikan kesembuhan. 
"Saya selalu memotivasi istri saya, ketika akan berangkat kontrol. Supaya istri saya mempunyai keyakinan bahwa penyakit ini pasti sembuh.”(P2)

"Saya sebagai istri selalu memberikan semangat untuk suami supaya bisa sehat lagi dan tidak menderita terus seperti ini."(P3)

"Saya banyak berdoa kepada Allah semoga suami saya cepet sembuh agar bisa bekerja kembali."'(P1)

Partisipan berharap upaya yang mereka lakukan membuat pasangan hidup mereka sembuh dan tidak mengalami kekambuhan tekait penyakit MDR TB. Partisipan juga berharap mereka dapat menjalani kehidupan yang normal kembali seperti saat sebelum pasangan mereka mengalami sakit.

"Saya tidak mau mengulang kejadian yang sama yaitu gagal dalam pengobatan."(P3)

"Saya berharap bisa hidup normal kembali."(P2)

\section{Tema 2 : Pasrah dalam menjalani hidup}

Partisipan mengungkapkan tentang pasangan hidupnya yang lelah dalam menjalani pengobatan. Partisipan merasakan sedih tetapi ikhlas ingin menggantikan sakit dari pasangan hidupnya karena dia merupakan tulang punggung keluarga.

"Istri saya merasa lelah dengan penyakitnya."(P2)

"Saya merasa sedih dengan kondisi istri saya. Saya ikhlas jika saya bisa menggantikan penyakit istri saya."(P3)

"Saya merasa sedih dan menggantikan peran suami saya untuk bekerja."(P1)

Pasangan hidup partisipan, merasa malu jika bertemu dengan orang lain dan pasrah terhadap keadaan sakit saat ini.

"Suami saya merasa malu jika harus bertemu dengan orang lain."(P1)

"Saya harus pasrah dan menggantikan suami saya untuk bekerja."(P2)

"Saya memberikan semangat kepada suami saya dan saya jalani bersama."(P3)

Respon partisipan terhadap pasangan hidup pasrah dan menjadi pengganti tulang punggung untuk keluarga.

"Saya harus pasrah dengan keadaan saat ini yang bekerja demi anak-anak."(P1)

"Saya merasa berat karena harus mengantarkan suami saya berobat ke RS setiap hari. Saya melakukan ini semua demi kesembuhan suami saya.’(P3)

Perasaan cemas timbul pada partisipan yaitu partisipan merasakan kecemasan dan kekhawatiran pada pasangan hidup. Hal ini disebabkan karena pasangan hidup tidak rutin berobat, mengganti pengobatan, masalah biaya transportaksi dan efek samping obat.

"Saya merasa keberatan masalah biaya karena harus mengantar suami berobat ke rumah sakit setiap hari."(P3)

"Kalau ada yang sakit seperti suami saya, jangan dijauhi, jangan dikucilkan tapi malah dibantu supaya tidak tambah parah."(P1)

"Banyak yang memberikan stigma negatif kepada keluarga kami, seolah-olah dianggap akan menularkan penyakit ini pada mereka itulah yang membuat kami sedih" (P2)

Di sisi lain partisipan juga mempunyai usaha untuk kesembuhan pasangan hidup yaitu dengan kesabaran dan memberikan semangat.

"Saya selalu memberikan semangat kepada suami saya."(P3)

"Saya memberikan semangat mendampingi istri saya untuk sembuh. Kalau bukan saya yang memberikan semangat, siapa lagi.”(P2) 
"Saya mempunyai keyakinan bahwa penyakit ini pasti sembuh."(P2)

"Saya selalu sabar mendampingi bapak."(P1)

Adanya penderitaan yang dialami oleh pasangannya menyebabkan partisipan merasa sedih dan mengungkapkan ikhlas apabila dia bisa menggantikan sakit yang dialami oleh pasangan hidupnya. Namun, seorang partispan mengungkapkan rasa bersyukur dalam kondisi yang dialami mereka, namun suami partisipan masih dapat mencari nafkah. Satu partisipan lainnya mengungkapkan bahwa penyakit yang diderita oleh pasangannya menyebabkan perubahan peran dalam keluarga, dimana peran dia sebagai ibu rumah tangga berubah menjadi pencari nafkah utama dalam keluarga.

"Mengapa harus istri saya? Kalau saya bisa menggantikan istri saya sakit, saya ikhlas."(P2)

"“'Saya beruntung sekali mbak, masih diberi cobaan hanya seperti ini. di luar sana banyak yang lebih parah dari keadaan saya."(P3)

"Sekarang saya yang harus mencari pekerjaan."(P1)

Partisipan juga harus berperan ekstra dalam mengantar pasangan untuk berobat ke rumah sakit. Partisipan mengungkapkan bahwa pengorbanan yang dilakukan untuk kesembuhan dari suaminya. Dua partisipan mengatakan bahwa mereka pasrah dengan takdir yang mereka harus jalani. Mereka percaya sebagai suami istri pengalaman suka dan duka harus dijalani bersama. Seorang partisipan mengeluhkan bahwa kehidupan yang dijalani sangat berat.

"Kami berdoa dan ikhtiar, kontrol rutin ke rumah sakit, saya selalu memotivasi istri saya."(P2)

““'Saya sudah pasrah dengan takdir. Ketika bapak sehat, bapak yang bekerja. Sekarang saya yang harus bekerja."(P1)

““'Saya sudah pasrah. Saya berdoa supaya istri saya kuat menghadapi ujian ini.”(P3)

\section{PEMBAHASAN}

Dari hasil penelitian didapatkan dua tema yaitu tantangan dalam merawat pasangan yang menderita MDR TB dan pasrah dalam menjalani hidup. Tantangan partisipan dalam merawat pasangan yang menderita MDR TB adalah pasangan partisipan mengalami perubahan fisik antara sebelum sakit dengan semenjak mengalami sakit.

Dari hasil penelitian didapatkan bahwa pasangan partisipan mengalami perubahan fisik seperti batuk, badan terasa dingin, berkeringat pada malam hari dan kesulitan dalam menelan obat. Hasil ini sesuai dengan penelitian yang dilakukan oleh Abrori yaitu pasien MDR TB mengalami perubahan fisik disebabkan sering mengalami batuk, badan terasa dingin, kadang sering berkeringat (Abrori \& Ahmad, 2018). Perubahan fisik selama menjalani pengobatan disebabkan karena efek samping obat seperti batuk, keringat dingin pada malam hari, pusing, mual, muntah, gatal, gangguan psikologis dan hilangnya nafsu makan (Hapsari, Dupai, \& Prasetya, 2018; Kemenkes RI, 2019).

Hasil penelitian menujukkan bahwa pasangan partisipan kadang merasa lelah dan bosan dalam menjalani pengobatan OAT lini kedua karena memiliki efek samping lebih besar daripada OAT lini pertama. Pasangan berusaha memberikan semangat supaya pasien tetap menyelesaikan pengobatan sampai tuntas. Berdasarkan pedoman dari Kemenkes pada tahun 2018 bahwa OAT lini kedua mempunyai efek samping obat yang lebih besar daripada OAT lini pertama yaitu gatal, mual, muntah, pusing, gangguan pendengaran, gangguan tidur, gangguan fungsi hati dan gangguan fungsi ginjal (Kementerian Kesehatan RI, 2018). Sikap pasrah dan ikhlas dari pasangan hidup pasien menunjukkan dampak positif terhadap kesembuhan pasien (Jauhar, Nursasi, \& Wiarsih, 2018). Pasien MDR TB menjadi ikhlas dan patuh menjalani pengobatan 
MDR TB karena contoh sikap dan dukungan pasangan untuk selalu mendampingi pengobatan (Aslamiyati et al., 2019)

Dari hasil penelitian didapatkan bahwa pasangan partisipan memiliki rasa malu dan cemas untuk bertemu dengan orang lain terutama dengan para tetangga dikarenakan khawatir jika pasangan partisipan dianggap menularkan penyakit pada orang lain. Menurut penelitian yang dilakukan Mustaqin bahwa pada awal pengobatan MDR TB, pasien akan mengalami kecemasan. Keadaan ini kemungkinan disebabkan oleh persepsi masyarakat terhadap pasien MDR TB yang salah karena memberikan stigma yang buruk terhadap pasien MDR TB (Mustaqin, Suryawati, \& Priyanto, 2017). Stigma masyarakat terhadap penyakit MDR TB yang ditandai dengan pengucilan dan penolakan dapat menyebabkan perasaan putus asa dan ketidakpatuhan pengobatan yang berdampak negatif selama proses menjalani pengobatan (Hapsari et al., 2018; Tang et al., 2015). Dukungan pasangan hidup untuk kesembuhan pasien berupa motivasi, semangat dalam menjalani pengobatan dan setia untuk mendampingi pengobatan di rumah sakit (Aslamiyati et al., 2019; Harniati, Syahrul, 2019). Motivasi dari pasangan tentang kedisiplinan minum obat, memberikan dukungan bahwa penyakit adalah ujian dari Tuhan Yang Maha Esa (Li, Munsiff, Tarantino, \& Dorsinville, 2010). Semangat dari keluarga dalam mengawasi minum obat serta berpola hidup sehat, sangat bermanfaat untuk pasien sehingga pasien patuh dalam menjalani pengobatan MDR TB (Safri et al., 2019).

Hasil penelitian menujukkan bahwa partisipan pasrah dalam menjalani hidup dengan cara berusaha sabar dalam mendampingi pasien dalam menjalani pengobatan MDR TB. Sikap sedih ditunjukkan oleh partisipan dikarenakan partisipan sekarang menjadi tulang punggung keluarga yang bekerja untuk memenuhi kebutuhan rumah tangga serta kebutuhan sekolah anak-anak. Berdasarkan penelitian yang dilakukan Fallis bahwa pasangan hidup memberikan semangat dan dukungan kepada pasien dalam menjalani pengobatan dengan cara menggantikan posisi pasien untuk bekerja. Pengetahuan tentang penyakit MDR TB membuat pasangan hidup pasien menjadi lebih sabar dan ikhlas dalam menjalani hidup bersama pasien MDR TB (Fallis, 2013). Motivasi pasangan hidup untuk kesembuhan pasien dengan menggantikan peran pasien ketika sakit membuat sikap pasrah, sabar dan ikhlas dalam merawat pasien dalam menjalani pengobatan dan mendukung pengobatan supaya pasien sembuh (Aslamiyati et al., 2019; Prawulandari \& Setyowati, 2018).

\section{SIMPULAN}

Hasil penelitian ini dapat disimpulkan bahwa pasangan hidup dari pasien MDR TB mempunyai perasaan khawatir, cemas apabila pengobatan MDR TB tidak berhasil dan terjadi kekambuhan. Pasangan hidup menerima kondisi dari pasien MDR TB dan mengevaluasi kejadian kekambuhan di masa lalu. Dukungan dari pasangan hidup sangat diperlukan untuk memberikan semangat dan motivasi selama pasien MDR TB menjalani pengobatan. Perubahan hubungan dan perasaan yang dialami harus bisa dikontrol untuk mendampingi pasangan hidup menjalani pengobatan MDR TB.

\section{SARAN}

Diperlukan upaya serius dari perawat, petugas kesehatan, pengawas minum obat dan pasangan hidup pasien MDR TB agar mampu mendampingi pasien MDR TB selama menjalani pengobatan sampai tuntas. 


\section{DAFTAR PUSTAKA}

Abrori, I., \& Ahmad, R. A. (2018). Kualitas hidup penderita tuberkulosis resisten obat di kabupaten Banyumas. Berita Kedokteran Masyarakat, 34(2), 56-61.

Aslamiyati, D. N., Wardani, R. S., Kristini, T. D., Masyarakat, F. K., Semarang, U. M., Kesehatan, D., \& Jawa, P. (2019). Faktor yang Berhubungan dengan Keberhasilan Pengobatan Tuberkulosis Paru ( Studi di Puskesmas Kedungmundu Kota Semarang ). 102108.

Dewi, I. I., Prabamurti, P. N., \& Indraswari, R. (2019). Dengan Peran Pmo Dalam Pemberian Obat Tb Pada Anak. 7, 434-440.

Fallis, A. (2013). Hubungan karakteristik, pengetahuan, sikap dan tindakan penderita tuberkulosis paru dengan kepatuhan monum obat. In Journal of Chemical Information and Modeling (Vol. 53). https://doi.org/10.1017/CBO9781107415324.004

Fonner, E., \& Drph, J. (2013). Pedoman manajemen terpadu pengendalian tuberkulosis resistan obat.

Hapsari, D. S. P. K., Dupai, L., \& Prasetya, F. (2018). Studi Kualitatif Perilaku Pasien Tuberkulosis Multi Drugs Resistant di Wilayah Kerja Puskesmas Poasia Kota Kendari Tahun 2017. Jimkesmas, 3(1), 1-10.

Harniati, Syahrul, T. T. (2019). Efek program manajemen diri pada pasien PPOK. 4(1), 74-80. Retrieved from https://scholar.google.co.id/scholar?start=20\&q=cerita+dengan+teman+kontrol+perilaku+al kohol+2019\&hl=id\&as_sdt=0,5

Jauhar, M., Nursasi, A. Y., \& Wiarsih, W. (2018). Self-Management Counseling and Physical Health Status among Patients with Pulmonary TB in Bogor, Indonesia. Nurse Media Journal of Nursing, 8(1), 35. https://doi.org/10.14710/nmjn.v8i1.16812

Kemenkes RI. (2019). Profil Kesehatan Indonesia 2018 [Indonesia Health Profile 2018]. Retrieved from http://www.depkes.go.id/resources/download/pusdatin/profil-kesehatanindonesia/Data-dan-Informasi_Profil-Kesehatan-Indonesia-2018.pdf

Kementerian Kesehatan RI. (2018). Laporan Hasil Riset Kesehatan Dasar (Riskesdas) Indonesia tahun 2018. Riset Kesehatan Dasar 2018, pp. 182-183.

Li, J., Munsiff, S. S., Tarantino, T., \& Dorsinville, M. (2010). Adherence to treatment of latent tuberculosis infection in a clinical population in New York City. International Journal of Infectious Diseases, 14(4), 292-297. https://doi.org/10.1016/j.ijid.2009.05.007

Manari, A., Ortolani, P., Guastaroba, P., Marzaroli, P., Menozzi, M., Magnavacchi, P., ... Marzocchi, A. (2011). Strategi nasional pengendalian tb. In Journal of Cardiovascular 
Medicine (Vol. 12). https://doi.org/10.2459/JCM.0b013e32833e58e4

Mustaqin, Suryawati, \& Priyanto, H. (2017). Hubungan Tingkat Kepatuhan Minum Obat Anti Tuberkulosis dengan Gejala Depresi pada Pasien TB Paru di RSUDZA Banda Aceh. Jurnal Ilmiah Mahasiswa Medisia, 2(2), 1-6. Retrieved from www.jim.unsyiah.ac.id/FKM

Nurhayati, I., Kurniawan, T., \& Mardiah, W. (2015). Perilaku pencegahan penularan dan faktorfaktor yang melatarbelakanginya pada pasien tuberculosis multidrugs resistance (TB MDR). Jurnal Keperawatan Padjadjaran, v3(n3), 166-175. https://doi.org/10.24198/jkp.v3n3.5

Prawulandari, A., \& Setyowati, D. (2018). Pengalaman Pasien Multi Drug Resistant Tuberkulosis (TB-MDR)Dalam Keberhasilan Pengobatan di Wilayah Kota Semarang. Retrieved from http://repository.unimus.ac.id

Safri, F. M., Sukartini, T., \& Ulfiana, E. (2019). Analisis Faktor Yang Berhubungan Dengan Kepatuhan Minum Obat Pasien Tb Paru Berdasarkan Health Belief Model Di Wilayah Kerja Puskesmas Umbulsari, Kabupaten Jember. Indonesian Journal of Community Health Nursing, 2(2). https://doi.org/10.20473/IJCHN.V2I2.11904

Tang, Y., Zhao, M., Wang, Y., Gong, Y., Yin, X., Zhao, A., ... Lu, Z. (2015). Non-adherence to anti-tuberculosis treatment among internal migrants with pulmonary tuberculosis in Shenzhen, China: A cross-sectional study. BMC Public Health, 15(1), 1-6. https://doi.org/10.1186/s12889-015-1789-z

Who. (2019). Regional and global profiles. Global Status Report of Tuberculosis, 251-258. Retrieved from www.who.int/tb/data 